\title{
Obstetrics outcome in pregnant women with cardiac disease in tertiary care center, Dehradun, India
}

\author{
Prachi Singh, Namrata Saxena*, Vineeta Gupta, Neeta Bansal, Yashika Pehal
}

\begin{abstract}
Department of Obstetrics and Gynecology, SMIH Hospital, Guru Ram Rai Institute of Medical and Health Sciences,
\end{abstract} College, Dehradun, Uttarakhand, India

Received: 06 November 2019

Accepted: 28 November 2019

\section{*Correspondence:}

Dr. Namrata Saxena,

E-mail: msnamrata30@gmail.com

Copyright: (C) the author(s), publisher and licensee Medip Academy. This is an open-access article distributed under the terms of the Creative Commons Attribution Non-Commercial License, which permits unrestricted non-commercial use, distribution, and reproduction in any medium, provided the original work is properly cited.

\begin{abstract}
Background: Incidence of heart disease in pregnancy is about $1 \%$. Pregnant patient with cardiac disease can present with lot of challenges for the obstetrician, paediatrician and the cardiologist. With improvement in diagnostic, medical, surgical management, more patient with cardiac diseases especially congenital are able to reach reproductive age. Therefore, still a cardiac disease remains a significant cause of maternal death. Maternal and fetal prognosis both is affected by the care given and the skills used in the treatment of the individual patient. Hospital has resulted in majority of cardiac disease patient being managed in a tertiary care center and this provide an opportunity to report on clinical experiences of pregnancy with cardiac disease, their management and obstetrical outcomes.

Methods: This was a retrospective study, with all the patients detailed demographic information, diagnosis, course in the hospital, management, maternal and fetal outcome was obtained from the medical records and files.

Results: Incidence of cardiac disease was found to be $0.7 \%, 47 \%$ of pregnant women fell in age group of 26-30 years, $38.2 \%$ were primigravida, only $23.53 \%$ were booked, and half of them belonged to NYHA II class. $73.5 \%$ had Rheumatic heart disease and the most common obstetrics complications were preterm labor and anemia. LSCS was done in $29.4 \%$ cases and $38.2 \%$ of the newborns were premature.

Conclusions: Prematurity anaemia, IUGR, are the common obstetrical complication in pregnant patient with cardiac disease which can be taken care with increased awareness and pre-conceptional counselling especially in patient with congenital heart disease. For optimization of maternal and neonatal outcomes in these patients, dedicated team of obstetrician, fetal medicine specialist, pediatricians, cardiologist and anesthesiologist is the prime requirement.
\end{abstract}

Keywords: Cardiac disease, Neonatal outcome, Obstetric outcome, Pregnant women

\section{INTRODUCTION}

Cardiac diseases in pregnancy categories these patients as high risk and require competent care throughout pregnancy as well during postpartum period. It requires a collaborative effort of obstetrician, paediatrician and the cardiologist to manage these patients. Developing countries like India still aiming to improve obstetric outcomes and institutional deliveries need better understanding of the disease related challenges for efficient policy making and planning. Rheumatic heart diseases together with congenital heart diseases among cardiac pathology hold lions share in etiology of cardiac diseases in India. ${ }^{1,2}$

The incidence of heart disease in pregnancy is about $1 \% .^{3}$ There are several ways by which maternal heart disease condition effects fetus and obstetric outcome. There is 
increased risk of spontaneous miscarriage as well as therapeutic abortion in women with heart disease. ${ }^{4}$ The overall risk of inheriting polygenic cardiac disease is 3$5 \%$ in babies born to mother with cardiac disease, as compared to $1 \%$ risk in the general population. ${ }^{5}$ This risk is further dependent on the condition of affected parent and there is an increased risk if any elder siblings are affected. The morbidity and mortality pattern of mother or the baby depends typically on the type of cardiac disease, its severity, functional status of mother and whether any complications associated with pregnancy exist or not. 6,7 Unfortunately, about $15-50 \%$ of the cardiac diseases are diagnosed during routine pregnancy related check-ups. Obstetric complications like anemia, preterm births, IUGR, further worsen the pregnancy outcome. $^{8}$ The reported studies are however scant in context of Northern India. The current paper aims to assess the maternal and fetal outcome among pregnant women with cardiac diseases at a tertiary care center in Dehradun.

\section{METHODS}

This study was a retrospective cross-sectional study done from January 2017 to December 2018 at obstetrics and gynecology department of Shri Guru Ram Rai Institute of Medical and Health Sciences and Shri Mahant Indresh Hospital (SGRRIMHS and SMIH), Dehradun. It is a tertiary care medical college and hospital catering to patients of Uttarakhand and neighboring places.

\section{Inclusion criteria}

- Patients admitted in obstetric ward or labour room of SGRRIMHS and SMIH with diagnosed cardiac disease during the study period were included in the study

- Both booked and unbooked cases were included in the study.

\section{Exclusion criteria}

- Those pregnant women not admitted in obstetric ward or labour room of SGRRIMHS and SMIH

- Those without diagnosed cardiac disease irrespective of any signs and symptoms.

A total of 34 patients who were admitted in obstetrics Ward and labour room, either booked or emergency case with confirmed diagnosis of cardiac disease were found and all of them were included in the study. All 34 patients included in the study were thoroughly examined, investigated and were under the follow up of the cardiologist.

The demographic information like age, parity, booking status personal details, obstetric history, NYHA class, type of cardiac lesion, duration of cardiac disease, indication of labor induction labor management, indication of caesarean section, fetal outcome, maternal peripartum and postpartum complications, like postpartum hemorrhage, cardiac failure, worsening of NYHA class, cause of maternal mortality, duration of hospital stay, etc were taken from patient's files, obstetrics ward and labour room records. All the data collected and analyzed to see the effects of cardiac disease on pregnancy course, labour complications, common challenges faced by specialist doctors' team, and impact on maternal and fetal outcome.

\section{Statistical analysis}

The data was entered in Microsoft Excel version 2017 and analyzed. Graphs were made using excel software. Categorical data was expressed in number and percentages.

\section{RESULTS}

Almost 50\% patient (16/34) fall between age group of 26 to 30 years. Incidence of cardiac disease was found to be $0.7 \%$ (Table 1 ).

Table 1: Maternal age wise distribution of study participants.

\begin{tabular}{|lll|}
\hline Age & Number & Percentage $(\%)$ \\
\hline$\leq 20$ years & 1 & $2.9 \%$ \\
\hline 21-25 years & 8 & $23.5 \%$ \\
\hline 26-30 years & 16 & $47.0 \%$ \\
\hline 31-35 years & 8 & $23.5 \%$ \\
\hline 36-40 years & 1 & $2.9 \%$ \\
\hline
\end{tabular}

Among 34 patients, $13(38.2 \%)$ patient were primigravida and $12(35.2 \%)$ were gravida 2 . Gravida 3 and gravida 4 were the females with one or 2 alive issues with abortions adding to their gravidity (Figure 1).

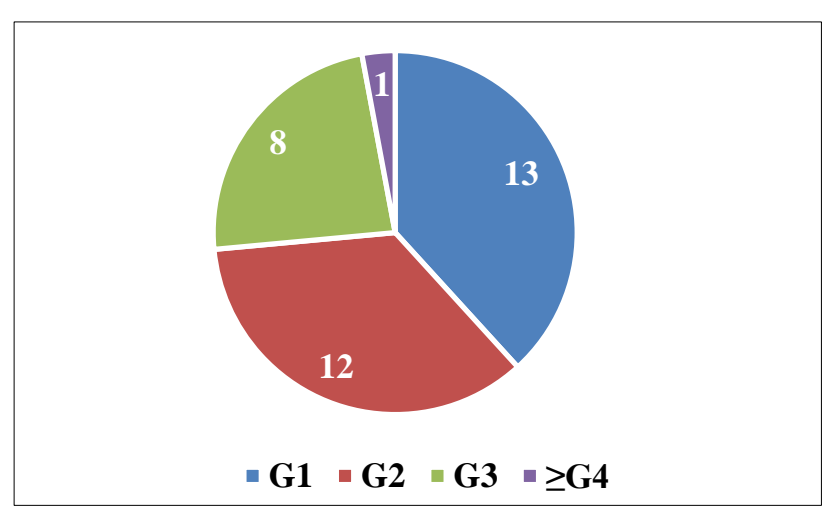

Figure 1: Distribution of study participants according to their gravida.

Out of total 34 patients with cardiac disease only 8 $(23.5 \%)$ were booked, rest $26(76.4 \%)$ were emergency admission and unbooked cases which clearly shows ignorance and lack of knowledge and facilities in developing countries (Table 2). 
Table 2: Booking status of study participants.

\begin{tabular}{|lll|}
\hline Booking status & Number & Percentage (\%) \\
\hline Booked & 8 & $23.53 \%$ \\
\hline Unbooked & 26 & $76.47 \%$ \\
\hline
\end{tabular}

In present study, maximum patient falls in NYHA class II $(50 \%)$, while $7(20.5 \%)$ patients fall in NYHA class I and III (Figure 2).

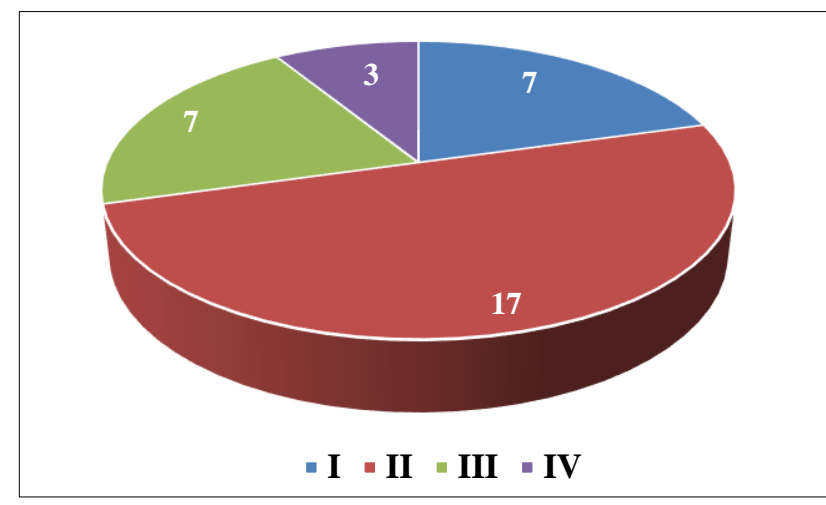

Figure 2: NYHA Classification wise distribution of study participants.

In present study, RHD still constitute the cause of cardiac disease in majority of $25(73.5 \%)$ pregnant females. 12 pregnant females had associated pulmonary hypertension ( 2 with CHD and 10 with RHD). The second most common cause of cardiac disease was Congenital heart disease in this study (Table 3).

Table 3: Distribution of study participants according to types of cardiac disease.

\begin{tabular}{|lll|}
\hline Cardiac disease & Number & Percentage (\%) \\
\hline Congenital heart disease & 7 & 20.5 \\
\hline Rheumatic heart disease & 25 & 73.5 \\
\hline Peripartum cardiomyopathy & 1 & 2.9 \\
\hline Associated pulmonary HTN & 12 & 35.2 \\
\hline $\begin{array}{l}\text { Others (paroxysmal } \\
\text { supraventricular tachycardia }\end{array}$ & 1 & 2.9 \\
\hline
\end{tabular}

The most common obstetrics complications were preterm births and anemia. 4 patients had postpartum hemorrhage. 2 patients landed in caesarean hysterectomy and 1 patient had VBAC and was explored under anesthesia for PPH and further medically managed. 1 patient with forceps delivery had atonic PPH managed with medical treatment and blood transfusion. In the present study author had 2 $(5.8 \%)$ maternal mortality and in both the patients NYHA class worsened resulting in the patient's death due to cardiac failure (Figure 3).

In the present study, maximum patient $24(70.5 \%)$ delivered vaginally. 3 patient had VBAC, these were the patients already in active labor at time of admission.10 patient underwent caesarean section. Among 4 patients cardiac indication were peripartum cardiomyopathy with $\mathrm{CHF}$, Eisenmenger complex, in rest 2 patient upgradation in NYHA functional class with CHF was the reason for LSCS (Table 4).

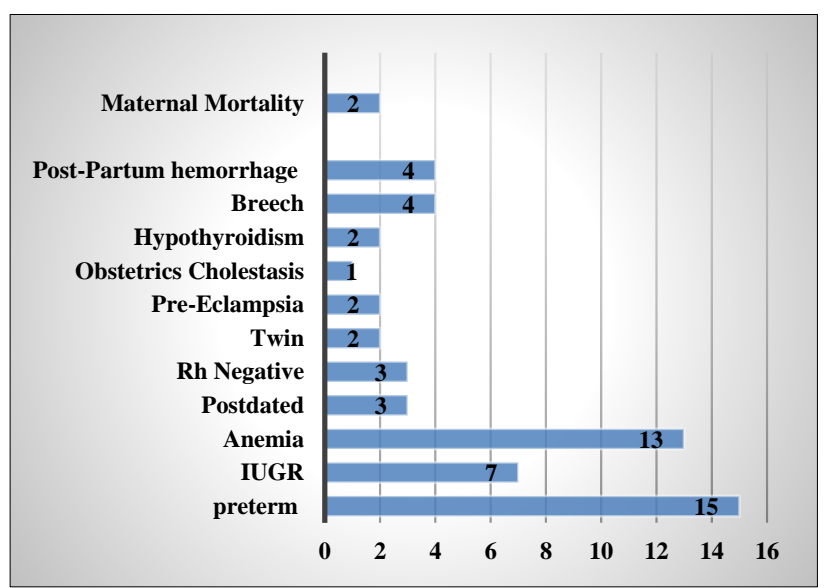

Figure 3: Horizontal bar diagram showing distribution of study participants according to obstetrics complications.

Table 4: Distribution of study participants according to mode of delivery.

\begin{tabular}{|lll|}
\hline Delivery & Numbers & $\begin{array}{l}\text { Percentage } \\
(\%)\end{array}$ \\
\hline Vaginal delivery & 24 & $70.5 \%$ \\
\hline VBAC & 3 & $8.8 \%$ \\
\hline Instrumental & 3 & $8.8 \%$ \\
\hline Induced & 4 & $11.7 \%$ \\
\hline LSCS & 10 & $29.4 \%$ \\
\hline Fetal distress & 2 & $5.8 \%$ \\
\hline Breech & 3 & $8.8 \%$ \\
\hline $\begin{array}{l}\text { Previous LSCS with prolonged } \\
\text { ruptured membrane }\end{array}$ & 1 & $2.9 \%$ \\
\hline Cardiac complications & 4 & $11.7 \%$ \\
\hline
\end{tabular}

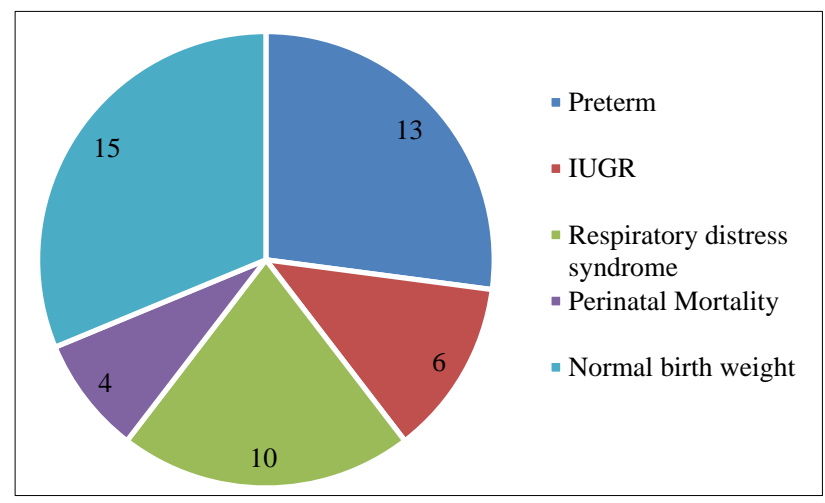

Figure 4: Distribution of study participants according to the neonatal outcome.

In this study prematurity $13(38.2 \%)$ is the commonest neonatal complication, $4(11.75 \%)$ perinatal mortality occurred in the present study out of them 2 were still 
birth and two babies were twin of 28 weeks gestation with very low birth weight of 600 gms and 660 gms (Figure 4).

\section{DISCUSSION}

The current study done at SGRRIMHS and SMIH Dehradun aimed to find the incidence of cardiac disease in pregnant women and maternal, neonatal outcome in such patients. The incidence of cardiac disease among pregnant women was found to be $0.7 \%$ in current study which was similar to Sneha P et al $(0.87 \%)$, Kothapalli ISK et al (1.23\%) and Mamatha S et al (1.75\%). In most of the studies, similar to this study, the foremost cause of cardiac disease was rheumatic heart disease. The prevalence of RHD varied from $73.5 \%$ in current study to $41.82 \%$ in study by Khan DA et al. Most of the patients belonged to NYHA class II similar to studies by Sneha P et al and Kothapalli ISK et al. The prevalence of normal vaginal delivery was highest in this study being $73.5 \%$ as compared to other studies. Likely, LSCS rate was $29 \%$ similar to that by Kothapalli ISK et al. The incidence of maternal death was $5.8 \%$ which was comparable with previous studies. However, the incidence of perinatal mortality was slightly higher in current study due to preterm labor, IUGR, anemia and other peripartum cardiac complications (Table 5).

Table 5: Comparative evaluation of study outcomes.

\begin{tabular}{|lllllll|} 
Parameter & $\begin{array}{l}\text { Current } \\
\text { study }\end{array}$ & $\begin{array}{l}\text { Salam S } \\
\text { et al }\end{array}$ & $\begin{array}{l}\text { Kothapalli } \\
\text { ISK et al }\end{array}$ & $\begin{array}{l}\text { Khan DA } \\
\text { et al }^{11}\end{array}$ & $\begin{array}{l}\text { Sneha P et } \\
\text { al }^{12}\end{array}$ & $\begin{array}{l}\text { Mamatha } \\
\text { S et al }^{13}\end{array}$ \\
\hline Incidence of cardiac disease & $0.7 \%$ & $4.3 \%$ & $1.23 \%$ & & $0.87 \%$ & $1.75 \%$ \\
\hline Prevalence of RHD & $73.5 \%$ & $56.6 \%$ & $\begin{array}{l}50 \% \text { (valvular } \\
\text { heart disease) }\end{array}$ & $41.82 \%$ & $60 \%$ & $52.5 \%$ \\
\hline NYHA class & II-50\% & & I-54\%, II-39\% & & II-66.89\% & I-91.8\% \\
\hline Spontaneous vaginal delivery & $70.5 \%$ & $41.2 \%$ & $56 \%$ & $28.84 \%$ & $38.83 \%$ & $44.3 \%$ \\
\hline LSCS & $29.4 \%$ & $36.2 \%$ & $29 \%$ & $42.30 \%$ & $41.67 \%$ & $52.5 \%$ \\
\hline Maternal death & $5.8 \%$ & $4.4 \%$ & & $10.34 \%$ & $2.79 \%$ & $1.6 \%$ \\
\hline Preterm & $38.2 \%$ & & & $38 \%$ & $2.78 \%$ & $3.3 \%$ \\
\hline Neonatal deaths & $11.75 \%$ & $2.6 \%$ & $3 \%$ & $0 \%$ & $2.78 \%$ & \\
\hline
\end{tabular}

\section{CONCLUSION}

In developing countries, women with rheumatic heart disease still comprise majority of pregnant women with cardiac disease at referral centre. NYHA class 1 and II are the patient with favorable outcome with good multidisciplinary approach. Prematurity, IUGR, anaemia are the common obstetrical complication in pregnant patient with cardiac disease which can be taken care with increased awareness and pre-conceptional counselling especially in patient with congenital heart disease. So, in order to optimize maternal and neonatal outcomes in these patients, dedicated team of obstetrician, fetal medicine specialist, paediatrician and cardiologist and anesthesiologist is the prime requirement.

Funding: No funding sources

Conflict of interest: None declared

Ethical approval: The study was approved by the Institutional Ethics Committee

\section{REFERENCES}

1. Shah TM, Mishra K, Ninama P, Parikh C. Cardiac diseases with pregnancy - a study of maternal and fetal outcome. IAIM. 2015;2(1):22-9.

2. Seckeler MD, Hoke TR. The worldwide epidemiology of acute rheumatic fever and rheumatic heart disease. Clin Epidemiol. 2011;3:67-84.
3. Bhatla N, Lal S, Behera G, Kriplani A, Mittal S, Agarwal $\mathrm{N}$ et al. Cardiac disease in pregnancy. Int $\mathrm{J}$ Gynecol Obstet. 2003;82(2):153-9.

4. Siu SC, Colman JM, Sorensen S, Smallhorn JF, Farine D, Amankwah KS, et al. Adverse neonatal and cardiac outcomes are more common in pregnant women with cardiac disease. Circulation. 2002;105:2179-84.

5. Romano Zelekha O, Hirsh R, Blieden L, Green M, Shohat T. The risk for congenital heart defects in offspring of individuals with congenital heart defects. Clin Genet. 2001;59:325-9.

6. Somerville J. Near misses and disasters in the treatment of grown-up congenital heart patients. J Royal Society Med. 1997;90(3):124-7.

7. Colman JM, Sui SC. Pregnancy in adult with congenital heart disease. Prog Paediatr Cardiol. 2003; 17:53-60.

8. Uebing A, Steer PJ, Yentis SM, Gatzoulis MA. Pregnancy and congenital heart disease. Br Med J. 2006;332(7538):401-6.

9. Salam S, Mushtaq S, Mohi-ud-Din K, Gul I, Ali A. Maternal and fetal outcome in pregnancy with heart disease in tertiary care hospital in India. Int J Reprod Contracept Obstet Gynecol. 2017;6(9):3947-51.

10. Kothapalli ISK, Basa A, Medapati NA. Clinical study of cardiac diseases during pregnancy in a tertiary care center, Kakinada. J Evolution Med Dent. Sci. 2019;8(33):2602-6. 
11. Khan DA, Sharma N, Kapoor M, Duwarah SG, Ahanthem SS. The spectrum of heart disease in pregnancy and its outcome in patients visiting a tertiary care centre of northeastern: a prospective study. J Clin Diagn Res. 2018;12:QC16-QC20.

12. Sneha P, Sarojamma C, Nagarathnamma R. Cardiac disease complicating pregnancy: a tertiary care center experience. J Med Sci. 2017;3(2):41-4.

13. Mamatha S, Pavithra J, Mahesh M, Madhumitha M. Obstetric outcome in pregnancies complicated by cardiac disease a study from a tertiary care hospital at Mysore South India. MedPulse - Int J Gynaecol. 2017;3(3):96-9.

Cite this article as: Singh $\mathrm{P}$, Saxena N, Gupta V, Bansal N, Pehal Y. Obstetrics outcome in pregnant women with cardiac disease in tertiary care center, Dehradun, India. Int J Reprod Contracept Obstet Gynecol 2020;9:313-7. 